\title{
Changes in biochemical factors, inflammatory mediators and prothrombotic acute phase proteins in patients with type 2 diabetes mellitus on 12 Months Of Dietary Modification
}

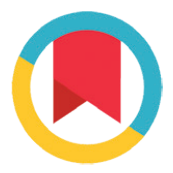

CrossMark

\author{
Sheu Kadiri Rahamon, ${ }^{1,2^{*}}$ Mabel Ayebatonyo Charles-Davies, ${ }^{1}$ Kehinde Sola Akinlade, \\ John Ayodele Olaniyi, ${ }^{3}$ Adesoji Adedipe Fasanmade,${ }^{4}$ Oyediran Emmanuel Oyewole, ${ }^{5}$ \\ Mayowa Ojo Owolabi, ${ }^{4}$ Jane Roli Adebusuyi, ${ }^{6}$ Olufunke Olayemi Hassan, ${ }^{6}$ \\ Muhammed Babatunde Ajobo, ${ }^{7}$ Kehinde Adigun, ${ }^{8}$ Maria Onomaghuan Ebesunun, ${ }^{9}$ \\ Omolara Olutosin Popoola, ${ }^{1}$ Wemimo Omiyale, ${ }^{1}$ Olatunbosun Ganiyu Arinola, ${ }^{2}$ \\ Emmanuel Oluyemi Agbedana ${ }^{1}$
}

*Correspondence to:

Sheu Kadiri Rahamon, Department of Chemical Pathology, College of Medicine, University of Ibadan, Ibadan, Nigeria. Department of Immunology, College of Medicine, University of Ibadan, Ibadan, Nigeria adekunlesheu@rocketmail.com

Cite This Article: Rahamon, S.K., Charles-Davies, M.A., Akinlade, K.S., Olaniyi, J.A., Fasanmade, A.A., Oyewole, 0.E., Owolabi, M.O., Adebusuyi, J.R., Hassan, 0.0., Ajobo, M.B., Adigun, K., Ebesunun, M.0., Popoola, 0.0., Omiyale, W., Arinola, 0.G. Agbedana, E.0. 2020. Changes in biochemical factors, inflammatory mediators and prothrombotic acute phase proteins in patients with type 2 diabetes mellitus on 12 Months Of Dietary Modification. Diabesity 6(4): 28-35. D01: 10.15562/ diabesity.2020.70

\section{ABSTRACT}

Background: Reports continue to show that lifestyle modification is cornerstone in the management of type 2 diabetes mellitus (T2DM). However, lifestyle and cultural patterns vary significantly across communities thereby necessitating the need for tailored dietary interventions to achieve optimal glycemic control. Presently, few prospective studies in Nigeria demonstrate the potential effects of diet modification on cardiometabolic, inflammation and prothrombotic factors. This study therefore assessed the effects of a twelvemonth dietary modification on cardiometabolic, inflammation and prothrombotic factors in individuals with T2DM.

Materials and Methods: Forty adults with T2DM were enrolled into this longitudinal study. They were placed on 20\%, 30\% and 50\% total caloric intake obtained from protein, fat, and carbohydrate respectively and were followed up for 12 months. Adherence to the dietary modification was assessed using a surrogate index. Standard methods were used to measure the blood pressure and anthropometric indices. Lipid profile, fasting plasma glucose (FPG), fibrinogen, plasminogen activator inhibitor-1 (PAI-1)], interleukin-6 (IL-6) and interleukin-10 (IL-10) were measured using spectrophotometric methods and ELISA as appropriate. Data analysis was done using paired Student's t-test,
Wilcoxon signed-rank test and Spearman correlation as appropriate. Pvalue less than 0.05 was considered as statistically significant. Results: There were no significant changes in the mean body weight, body mass index (BMI), hip circumference $(\mathrm{HC})$, waist-hip ratio, systolic (SBP) and diastolic (DBP) blood pressure, FPG and low density lipoprotein-cholesterol (LDL-C) at 6 months and 12 months compared with the baseline. However, the mean levels of high density lipoprotein-cholesterol (HDLC) was significantly elevated while the mean waist circumference (WC) and waist- to-height ratio (WHtR) were significantly reduced at 12- month compared with baseline. Interleukin-10 (IL-10) level was significantly higher at 6months compared with the baseline but reduced significantly at 12-month compared with the 6-month level. Unexpectedly, there was significant progressive rise in the median level of fibrinogen at 6-month and 12-month compared with the baseline. Similarly, plasminogen activator inhibitor-1 (PAI-1) levels at 6-month and 12-month were significantly higher compared with the baseline.

Conclusion: It could be concluded from this study that twelve months of dietary modification improved central adiposity and high density lipoprotein-cholesterol but could not halt prothrombosis.
Keywords: Central adiposity, Dietary intervention, Inflammation, Prothrombosis, Type 2 diabetes mellitus.

\section{INTRODUCTION}

Diabetes mellitus is a global public health problem as its prevalence continues to rise worldwide. The International Diabetes Federation (IDF) reported that 463 million adults live with diabetes in the year
2019 and estimated that by 2045, it will be around 700 million. ${ }^{1}$ Of the adults living with diabetes, $79 \%$ live in low- and middle-income countries. In 2015, there were $1,702,900$ cases of diabetes in Nigeria. ${ }^{2}$

\footnotetext{
'Department of Chemical Pathology, College of Medicine, University of Ibadan, Ibadan, Nigeria

${ }^{2}$ Department of Immunology, College of Medicine, University of Ibadan, Ibadan, Nigeria.

${ }^{3}$ Department of Haematology, College of Medicine, University of Ibadan, Ibadan, Nigeria.

${ }^{4}$ Department of Medicine, College of Medicine, University of Ibadan, Ibadan, Nigeria

${ }^{5}$ Department of Health Promotion and Education, College of Medicine, University of Ibadan, Ibadan, Nigeria

${ }^{6}$ Department of Medical Social Services, University College Hospital, Ibadan, Nigeria

${ }^{7}$ Dietetics Department, University College Hospital, Ibadan, Nigeria

${ }^{8}$ Department of Family Medicine, University College Hospital, Ibadan, Nigeria

${ }^{9}$ Department of Chemical Pathology, College of Health Sciences, Olabisi Onabanjo University, Ago-Iwoye, Nigeria
} 
Reports have shown that type 2 diabetes mellitus (T2DM) constitutes about 90 to $95 \%$ of all diabetes. This has been attributed to rapid cultural and social changes, ageing, increased urbanization, dietary changes, reduced physical activity and other unhealthy lifestyle and behavioural patterns. ${ }^{3,4}$

T2DM is a major cause of morbidity and premature mortality hence, a holistic approach to T2DM care is usually advocated..$^{5}$ An important component of T2DM care is dietary management which is based on the principle of healthy eating in the context of social, cultural and psychological influences on food choices. ${ }^{6}$ The goals of dietary management in diabetes care are diverse. These include promotion and support of healthful eating patterns with emphasis on a variety of nutrient dense foods in appropriate portion sizes in order to improve overall health; addressing individual nutrition needs based on personal and cultural preferences, health literacy and numeracy, access to healthful food choices, willingness and ability to make behavioural changes, as well as barriers to change; maintenance of the pleasure of eating by providing non-judgmental messages about food choices; and provision of practical tools for day-to-day meal planning rather than focusing on individual macronutrients, micronutrients or single foods. These goals will help in achieving and maintaining body weight goals, attaining individualized glycemic, blood pressure, and lipid goals, and prevention or delay of complications of diabetes. ${ }^{4-7}$

Several studies have shown that healthy dietary habits and regular exercise are beneficial in the prevention and management of T2DM-related morbidity and mortality. ${ }^{8-10}$ However, lifestyle and cultural patterns vary significantly, across and even within communities. To achieve effectiveness, acceptability and sustainability therefore, dietary interventions should be tailored according to regional and ethnic differences. ${ }^{11,12}$ We have previously shown that $6-12$ months of dietary modification resulted in substantial cardiometabolic, inflammatory and prothrombotic improvements in adults with metabolic syndrome (MS). ${ }^{14}$ This study was therefore designed to find out if the dietary modification that resulted in improved cardiometabolic, inflammatory and prothrombotic profile in adults with MS would result, when used in conjunction with the regular antidiabetic medications, in meaningful changes in markers of glycaemia, blood pressure, lipid, inflammation and prothrombosis in adults with T2DM.

\section{MATERIALS AND METHODS}

\section{Study participants}

A total of 40 adults with T2DM attending the Endocrinology Clinic, Medical Outpatient Unit,
University College Hospital, Ibadan were enrolled into this longitudinal study using convenient sampling. The patients were participants in a study titled "Risk Assessment of Type 2 Diabetes mellitus and Dementia in Nigerians with Metabolic Syndrome". ${ }^{15}$ The patients were diagnosed using the World Health Organization criteria as venous fasting plasma glucose (FPG) value of $\geq 7.0 \mathrm{mmol} / \mathrm{L}$ $(126 \mathrm{mg} / \mathrm{dl})$, or random plasma glucose value of $\geq 11.1 \mathrm{mmol} / \mathrm{L}$ ( $200 \mathrm{mg} \mathrm{dl} / \mathrm{l})$, or plasma glucose value of $\geq 11.1 \mathrm{mmol} / \mathrm{L}(200 \mathrm{mg} / \mathrm{dl}) 2$ hours after a $75 \mathrm{~g}$ oral load. ${ }^{3}$ The study participants were not newly diagnosed and were not on statins. A large proportion of the patients were on oral anti-diabetic drugs (mainly metformin and glibenclamide and pioglitazone hydrochloride) of different dosage while only a few were on insulin.

\section{Ethical consideration}

Ethical approval was obtained from the University of Ibadan/University College Hospital (UI/UCH) Joint Ethics Committee. Also, written informed consent was obtained from each participant before enrolment into the study.

\section{Inclusion and exclusion criteria}

The study participants were adults with diabetes mellitus who were 18 years or older and had been attending the Clinic for at least 3 months. Patients who were $<18$ years, critically ill, pregnant and those that did not give informed consent were excluded from the study.

\section{Dietary prescription}

The dietary prescription was as described previously. ${ }^{14}$ Briefly, a Principal Dietician had a comprehensive consultation with all the study participants. The need for behavioural change such as dietary modification and different cooking methods were explicitly discussed. Individual dietary intake was assessed using a 24-hour dietary recall. Based on the information provided by the patients which showed that their daily caloric intake was largely (approximately 70\%) carbohydrate based, the total caloric intake obtained from protein, total fat and carbohydrate was calculated and pegged at $20 \%$, $30 \%$ (including $14 \%$ polyunsaturated fat) and $50 \%$ respectively. The dietary prescription was structured following the Therapeutic Life-Style Changes diet recommendation. ${ }^{16}$ Verbal and written instructions containing list of recipes and quantities of different foods to be consumed to meet the desired dietary requirement were provided to each participant. The participants were advised to adhere to the dietary advice in addition to the use of oral antidiabetic drugs or insulin as recommended by their Physicians. 


\section{Follow up of the participants}

Each participant was seen monthly for 12 months by the Dietician and information on compliance was obtained using a 24-hour dietary recall. Clinical assessment of compliance was done by calculating the waist-to-height ratio (WHtR); an index of dietary adherence. ${ }^{17}$

\section{Sample collection}

After an overnight fast of about $10-12 \mathrm{hr}, 15 \mathrm{ml}$ of blood was obtained from each participant at baseline (before the commencement of dietary modification), 6 months and 12 months (post-dietary modification). Reminder telephone calls were made to each participant prior to their scheduled 6- and 12-months visits. Samples were dispensed into appropriate bottles and serum and plasma samples obtained were stored at $-20^{\circ} \mathrm{C}$ until analysed.

\section{Measurement of anthropometric indices}

The height of each participant was measured in meters with subjects standing bare footed on a stadiometer. The body weight was taken with an Omron (Bf 400) weighing scale placed on a flat surface while the participants wore light clothing with no shoes. The reading was recorded in kilogram $(\mathrm{kg})$. Thereafter, the body mass index (BMI) was calculated as the ratio of body weight $(\mathrm{kg})$ to the square of height $(\mathrm{m})$. Waist circumference was measured using a measuring tape placed between the lower rib margins and the iliac crest while the hip circumference was measured at the widest circumference of the hip over light clothing, using a non- stretchable measuring tape. The waist-hip ratio (WHR) was calculated as the ratio of waist circumference to the hip circumference while the waist-height ratio (WHtR) was calculated by dividing the waist circumference by the height. The percentage body fat was measured using the bioelectrical impedance method (Omron BF 400, UK). The values were recorded in $\%$.

\section{Blood pressure measurement}

The diastolic and systolic blood pressure readings were taken twice with the use of mercury sphygmomanometer by a Physician after the patients have rested for at least ten minutes and in a sitting position. The mean values were recorded in $\mathrm{mmHg}$ according to the standard procedures.

\section{Laboratory analyses}

Determination of fasting plasma levels of glucose, total cholesterol (TC), triglyceride (TG) and high density lipoprotein cholesterol (HDLc) were determined using enzymatic method while the plasma level of low density lipoprotein cholesterol (LDLc) was calculated using the Frieldwald et al. ${ }^{18}$ formula. Serum concentrations of interleukins 6- and -10 (IL-6, IL-10), plasminogen activator inhibitor-1 (PAI-1) and fibrinogen were determined using sandwich ELISA (Boster Biological Technology Co., Inc, USA and Assaypro LLC, USA).

\section{Statistical analysis}

Statistical analysis was carried out using SPSS software, version 17.0. Histogram was used to assess the Gaussian distribution of all the continuous variables. Values are reported as mean \pm standard deviation or median (interquartile range) as appropriate. Differences in means/medians were determined using paired Student's t-test or Wilcoxon signed-rank test as appropriate. The relationship between all the variables was assessed using Spearman correlation. $P$-values less than 0.05 were considered as statistically significant.

\section{RESULTS}

Changes in anthropometric, clinical and cardiometabolic indices of the study participants after 12 months of dietary modification are shown in Table 1. Only HDLc had progressive rise in concentration from baseline through 12 months. There were no significant changes in the mean body weight, BMI, HC, waist-hip ratio, systolic and diastolic blood pressure, fasting plasma glucose (FPG) and LDLc at 6 months and 12 months compared with the baseline. The mean levels of HDLc, TC and TG were significantly elevated while WC and WHtR were significantly reduced at 12-month compared with baseline. Also, HDLc and TC were significantly elevated while body fat was significantly reduced at 12 -month compared with 6-month.

The median level of IL-10 was significantly higher at 6-month compared with the baseline but reduced significantly at 12 -month (paralleling the baseline) compared with the 6-month level. Unexpectedly, there was significant progressive rise in the median level of fibrinogen at 6-month and 12-month compared with the baseline. Similarly, the median levels of PAI-1 at 6-month and 12-month were significantly higher compared with the baseline (Table 2).

As shown in Table 3, WC had significant positive correlation with body weight, BMI, HC, waist-hip ratio and body fat. Also, HDLc had significant positive correlation with IL-10, TC and PAI-1. In addition, SBP and DBP had significant positive correlation with BMI, HC and body fat. 
Table 1 Anthropometric, Clinical and Cardiometabolic Indices in T2DM Patients at Baseline, 6 months and 12 months

\begin{tabular}{|c|c|c|c|}
\hline & Baseline $(n=40)$ & 6-month $(n=40)$ & 12-month $(n=40)$ \\
\hline Body weight (kg) & $67.8 \pm 12.0$ & $67.1 \pm 11.8$ & $67.4 \pm 11.5$ \\
\hline BMI $\left(\mathrm{kg} / \mathrm{m}^{2}\right)$ & $25.2 \pm 3.5$ & $24.8 \pm 3.4$ & $24.9 \pm 3.4$ \\
\hline Waist circumference $(\mathrm{cm})$ & $94.6 \pm 9.1$ & $90.5 \pm 16.6$ & $91.1 \pm 9.3^{\text {a } \dagger}$ \\
\hline Hip circumference $(\mathrm{cm})$ & $96.7 \pm 7.6$ & $96.9 \pm 7.4$ & $94.6 \pm 11.3$ \\
\hline Waist-Hip ratio & $0.98 \pm 0.06$ & $0.97 \pm 0.07$ & $0.97 \pm 0.12$ \\
\hline WHtR & $58.0 \pm 5.4$ & $55.3 \pm 10.2$ & $55.8 \pm 6.3^{\mathrm{a \dagger}}$ \\
\hline Body fat (\%) & $32.4 \pm 11.7$ & $29.7 \pm 8.8$ & $31.3 \pm 8.1^{\mathrm{b \dagger}}$ \\
\hline Systolic BP (mmHg) & $124.4 \pm 16.7$ & $127.5 \pm 20.4$ & $130.3 \pm 19.9$ \\
\hline Diastolic BP (mmHg) & $75.1 \pm 6.8$ & $75.0 \pm 9.3$ & $74.0 \pm 9.0$ \\
\hline $\mathrm{FPG}(\mathrm{mg} / \mathrm{dl})$ & $128.1 \pm 47.8$ & $112.2 \pm 44.2$ & $114.7 \pm 39.1$ \\
\hline $\mathrm{TC}(\mathrm{mg} / \mathrm{dl})$ & $151.2 \pm 45.1$ & $155.2 \pm 38.1$ & $171.1 \pm 42.2^{a \ddagger, b \neq}$ \\
\hline $\mathrm{TG}(\mathrm{mg} / \mathrm{dl})$ & $72.6 \pm 30.4$ & $73.2 \pm 29.1$ & $84.6 \pm 35.9^{\mathrm{a} \neq}$ \\
\hline $\operatorname{HDLc}(\mathrm{mg} / \mathrm{dl})$ & $37.0(22.5-48.3)$ & $47.0(37.3-55.5)^{\mathrm{a} \ddagger}$ & $53.5(38.3-91.8)^{a \neq, b \neq}$ \\
\hline $\mathrm{LDLc}(\mathrm{mg} / \mathrm{dl})$ & $100.5 \pm 38.7$ & $89.3 \pm 33.3$ & $90.9 \pm 40.5$ \\
\hline
\end{tabular}

Values are in mean \pm standard deviation or median (interquartile range), $\mathrm{n}=$ number of participants, T2DM = type 2 diabetes mellitus, ${ }^{\text {at }}$ significantly reduced when compared with baseline, ${ }^{\mathrm{a}}{ }^{\ddagger}$ significantly increased compared with baseline, ${ }^{\text {bt }}$ significantly reduced compared with 6 -month, ${ }^{\text {b* }}$ significantly increased compared with baseline, $\mathrm{BP}=$ blood pressure, $\mathrm{BMI}=$ body mass index, $\mathrm{WC}=$ waist circumference, $\mathrm{HC}=$ Hip circumference, $\mathrm{WHtR}=$ waist-to-height ratio, $\mathrm{FPG}=$ fasting plasma glucose, $\mathrm{TC}=$ total cholesterol, $\mathrm{TG}=$ triglyceride, $\mathrm{HDLc}=$ high density lipoprotein cholesterol, $\mathrm{LDLc}=$ low density lipoprotein cholesterol.

Table 2 Indices of Inflammation and Prothrombosis in T2DM Patients at Baseline, 6 months and 12 months

\begin{tabular}{lccc}
\hline & Baseline $(\mathbf{n}=\mathbf{4 0})$ & 6-month $(\mathbf{n}=\mathbf{4 0})$ & 12-month $(\mathbf{n}=\mathbf{4 0 )}$ \\
\hline IL-6 $(\mathrm{pg} / \mathrm{ml})$ & $0.74(0.74-49.8)$ & $27.1(0.74-75.3)$ & $13.0(0.74-72.7)$ \\
IL-10 $(\mathrm{pg} / \mathrm{ml})$ & $90.2(59.6-171.1)$ & $151.6(120.9-271.9)^{\mathrm{a} \neq}$ & $93.0(48.5-152.9)^{\mathrm{b} \dagger}$ \\
Fibrinogen $(\mu \mathrm{g} / \mathrm{ml})$ & $1519.9(1075.5-2361.4)$ & $3298.2(1845.6-5039.0)^{\mathrm{a} \neq}$ & $7370.2(5237.8-11714.2)^{\mathrm{a} \neq, \mathrm{b} \neq}$ \\
PAI-1 $(\mathrm{ng} / \mathrm{ml})$ & $4.9(4.6-5.0)$ & $5.2(5.0-5.3)^{\mathrm{a} \neq}$ & $5.2(5.0-5.2)^{\mathrm{a} \neq}$ \\
\hline
\end{tabular}

Values are in median (interquartile range), $\mathrm{n}=$ number of participants, $\mathrm{T} 2 \mathrm{DM}=$ type 2 diabetes mellitus, ${ }^{\mathrm{a}}$ significantly reduced when compared with baseline, ${ }^{a \neq}$ significantly increased compared with baseline, ${ }^{\text {b† }}$ significantly reduced compared with 6 -month, ${ }^{\text {b }}$ significantly increased compared with baseline, IL $=$ interleukin, PAI = plasminogen activator inhibitor

Table 3 Correlation between Selected Cardiometabolic Factors and Blood Pressure at Baseline

\begin{tabular}{lcccccc}
\hline & WC & FPG & TG & HDLC & SBP \\
\hline Body weight & $0.631,0.000^{* *}$ & $0.171,0.291$ & $0.099,0.543$ & $-0.106,0.517$ & $0.291,0.072$ & $0.340,0.034^{*}$ \\
BMI & $0.758,0.000^{* *}$ & $0.181,0.264$ & $0.196,0.225$ & $-0.197,0.223$ & $0.428,0.007^{\star *}$ & $0.401,0.011^{\star}$ \\
HC & $0.717,0.000^{* *}$ & $0.193,0.274$ & $0.041,0.819$ & $-0.029,0.869$ & $0.427,0.012^{\star}$ & $0.472,0.005^{* *}$ \\
Waist-hip ratio & $0.573,0.000^{* *}$ & $0.125,0.481$ & $0.295,0.090$ & $0.145,0.414$ & $-0.069,0.698$ & $-0.301,0.084$ \\
Body fat & $0.445,0.008^{* *}$ & $0.059,0.717$ & $0.283,0.076$ & $-0.214,0.185$ & $0.380,0.017^{*}$ & $0.400,0.012^{*}$ \\
IL-10 & $-0.002,0.991$ & $0.040,0.806$ & $0.084,0.606$ & $0.413,0.008^{* *}$ & $-0.058,0.726$ & $-0.297,0.067$ \\
IL-6 & $-0.032,0.859$ & $0.173,0.287$ & $-0.053,0.747$ & $0.160,0.325$ & $0.041,0.804$ & $-0.086,0.602$ \\
Fibrinogen & $-0.061,0.730$ & $-0.011,0.948$ & $0.169,0.297$ & $-0.083,0.611$ & $-0.193,0.239$ & $-0.103,0.534$ \\
PAI-1 & $-0.025,0.890$ & $0.212,0.190$ & $0.051,0.755$ & $0.327,0.039^{*}$ & $0.044,0.792$ & $0.149,0.365$ \\
TC & $-0.028,0.876$ & $0.212,0.190$ & $0.007,0.968$ & $0.555,0.000^{* *}$ & $0.054,0.745$ & $0.160,0.330$ \\
LDLc & $0.069,0.698$ & $0.190,0.241$ & $-0.061,0.708$ & $0.284,0.075$ & $-0.037,0.824$ & $0.174,0.288$ \\
\hline
\end{tabular}

Values are reported as r-value, $\mathrm{p}$-value, ${ }^{* *}$ significantly correlated at 0.01 level, ${ }^{*}$ significantly correlated at 0.05 level, $\mathrm{BMI}=$ body mass index, WC $=$ waist circumference, $\mathrm{SBP}=$ systolic blood pressure, $\mathrm{DBP}=$ diastolic blood pressure, $\mathrm{HC}=$ Hip circumference, $\mathrm{FPG}=$ fasting plasma glucose, $\mathrm{TC}=$ total cholesterol, $\mathrm{TG}=$ triglyceride, $\mathrm{HDLc}=$ high density lipoprotein cholesterol, $\mathrm{LDLc}=$ low density lipoprotein cholesterol, $\mathrm{IL}=$ interleukin, $\mathrm{PAI}=$ plasminogen activator inhibitor. 


\section{DISCUSSION}

Lifestyle modification is cornerstone in the management of T2DM. ${ }^{19}$ It is essential for optimal glycemic control and for preventing diabetes complications. ${ }^{20}$ However, the benefit accrued to lifestyle modification in T2DM care is usually not optimized due to patients' poor adherence. It has been reported in several studies that poor adherence to healthy lifestyle recommendations is prevalent amongst patients with T2DM. ${ }^{20-24}$ This has unfortunately, been resulting in frequent hospitalisations with its attendant high health care costs. ${ }^{25}$

The observed reduction in the mean WC at 6-month and at 12-month compared with baseline indicates reduction in central adiposity, which could be as a result of redistribution of body fat. A similar observation was reported by Eriksson and Lindgärde ${ }^{26}$ which showed that significant reduction in anthropometric indices was achieved following dietary modification.

Reports have shown that WHR and WHtR are better indices of central adiposity than WC. ${ }^{27,28}$ The observed progressive reduction in the mean WHtR post-dietary modification corroborates the observed reduction in WC and may thus suggest that there was an appreciable adherence to the dietary modification. Martínez-González et al. ${ }^{17}$ reported an inverse association between WHtR and adherence to the Mediterranean diet.

Intentional weight loss is associated with a significant reduction in all-cause mortality in overweight and obese T2DM patients. ${ }^{19,29}$ The Look AHEAD (Action for Health in Diabetes) trial showed that intensive lifestyle intervention (ILI) facilitates significant weight loss over a short and extended period of time..$^{30-32}$ In this study, reductions in the mean body weight and BMI were not significant. This observation contradicts the report of Eriksson and Lindgärde ${ }^{26}$ and could be due to disparities in selection of participants in the different studies. In this study, the participants were gender-matched ( 20 males and 20 females) and were not obese but were slightly overweight $\left(25.2 \mathrm{~kg} / \mathrm{m}^{2}\right)$. It could therefore, imply that dietassociated reduction in body weight and BMI is substantial in T2DM patients that are considerably overweight or obese.

Modest reduction in body weight is associated with improvements in lipid profile, insulin level, and glycemic control. ${ }^{33,34}$ This supports the observed increase in HDLc at 6-month and 12 -month post-dietary modification. This observation indicates improved cardioprotection following the short term dietary modification. This is further buttressed by the observed reduction, albeit insignificant, in LDLc level, a component of non-HDLc, post dietary modification. nonHDLc (defined as total cholesterol minus HDLc) which denotes the cholesterol contained in VLDL, IDL, and LDL particles is considered a better predictor of cardiovascular events and mortality in patients with DM. ${ }^{35,36}$ Unfortunately, the mean level of TG was significantly elevated at 12 -month compared with baseline. This observation indicates that there is the need for downward review of the percentage total caloric intake obtained from total fat $(30 \%)$ to optimize the observed associated increase in HDLc level.

A considerable weight loss of $>5 \%$ has been reported to be necessary for any substantial improvement on blood pressure. ${ }^{37} \mathrm{~A}$ non-significant decrease in systolic and diastolic BP has been reported in T2DM patients following 12 months of lifestyle intervention. ${ }^{38-44}$ These earlier reports support the observed non-significant changes in SBP and DBP in this study. This observation, together with other previous reports, probably indicates that dietary management might not be an effective strategy in the control of BP especially, in non-obese diabetics. It can thus be suggested that lifestyle interventions be used as adjunct to pharmacotherapy in the control of BP.

Disordered inflammatory and prothrombosis pattern has been reported in T2DM patients. ${ }^{45}$ Similarly, insulin-sensitizing drugs such as thiazolidinediones have been shown to possess anti-inflammatory and pro-adipogenic effects. ${ }^{46}$ A major limitation of this study was the enrolment of T2DM patients on insulin and oral anti-hyperglycaemic drugs instead of drug-naïve T2DM patients that will be placed on nutritional management only. These drugs can modulate the inflammatory homeostasis and obscure the effect of dietary modification. The influence of drugs might be responsible for the observed higher levels of fibrinogen and PAI-1 at 6-months and 12-months compared with baseline. Similarly, IL-10 which was significantly higher at 6-months reduced significantly at 12 -months. These observations, which cannot be explained presently, could be due to the influence of some of the drugs (since most diabetics are on poly-pharmaceutical therapy) being taken by the participants on the acute phase reactants and inflammatory cytokines.

Considering the relationship between the parameters, HDLc had significant positive correlation with IL-10 and TC. This is in line with the report of van Exel et al. ${ }^{47} \mathrm{IL}-10$ and HDLc have 
been reported to have potent anti-inflammatory and anti-atherosclerosis properties. The positive correlation between HDLc and TC indicates that there is corresponding increase in total cholesterol as HDLc increases. This is not surprising as HDLc is a component of the TC. In addition, SBP and DBP had significant positive correlation with BMI, HC and body fat. This observation is not unexpected as it is widely established that hypertension is linked with overweight and obesity. ${ }^{48,49}$

It could be concluded from this study that twelve months of dietary modification improved central adiposity and HDLc but could not halt prothrombosis. To fully understand the impact of dietary modification on inflammation and prothrombosis in T2DM, studies with strict adherence to dietary modification over an extended period of time is suggested in drug-naïve individuals with T2DM.

\section{SUPPORT}

This research was partly funded by the 2009 Multidisciplinary Research Grant of the University of Ibadan MacArthur Foundation and the University of Ibadan Senate Research Grant (SRG/ COM/2010/2C).

\section{CONFLICT OF INTEREST}

The authors have no competing interests to declare.

\section{AUTHORS' CONTRIBUTIONS}

The authors contributed to the intellectual content of this paper and have met the following requirements: a) Significant contributions to the concept and design, data acquisition, analysis and interpretation; b) Drafting and reviewing the article for intellectual content; c) Final approval of the article for publication.

\section{REFERENCES}

1. International Federation Federation. Diabetes Facts and Figures. 2019 [cited 2019 15th Nov.]. Available from: https:// HYPERLINK "http://www.idf.org/aboutdiabetes/ what-is-diabetes/facts-figures.html” www.idf.org/aboutdiabetes/what-is-diabetes/facts-figures.html.

2. International Diabetes Federation. IDF Africa members. 2019 [cited 2019 15th November, 2019.]. Available from: https://idf.org/our-network/regions-members/africa/ members/20-nigeria.html.

3. World Health Organization. Screening for type 2 diabetes: report of a World Health Organization and International Diabetes Federation meeting. Geneva: World Health Organization, 2003.

4. Lifestyle Management: Standards of Medical Care in Diabetes-2019. Diabetes care. 2019;42(Suppl 1):S46s60. Epub 2018/12/19. doi: 10.2337/dc19-S005. PubMed PMID: 30559231.
5. Standards of Medical Care in Diabetes-2020 Abridged for Primary Care Providers. Clinical diabetes: a publication of the American Diabetes Association. 2020;38(1):10-38. Epub 2020/01/25. doi: 10.2337/cd20-as01. PubMed PMID: 31975748; PubMed Central PMCID: PMCPmc6969656.

6. Ekore R, Ekore J. Dietary management of diabetes: a practical approach for primary care physicians in Nigeria. 2008.

7. Gray A, Threlkeld RJ. Nutritional recommendations for individuals with diabetes. Endotext [Internet]: MDText. com, Inc.; 2019.

8. Knowler WC, Barrett-Connor E, Fowler SE, Hamman RF, Lachin JM, Walker EA, et al. Reduction in the incidence of type 2 diabetes with lifestyle intervention or metformin. The New England journal of medicine. 2002;346(6):393-403.

9. The Diabetes Prevention Program (DPP): description of lifestyle intervention. Diabetes care. 2002;25(12):21652171. Epub 2002/11/28. doi: 10.2337/diacare.25.12.2165. PubMed PMID: 12453955; PubMed Central PMCID: PMCPmc1282458.

10. Wadden TA, West DS, Delahanty L, Jakicic J, Rejeski J, Williamson $\mathrm{D}$, et al. The Look AHEAD study: a description of the lifestyle intervention and the evidence supporting it. Obesity (Silver Spring, Md). 2006;14(5):737-752. Epub 2006/07/21. doi: 10.1038/ oby.2006.84. PubMed PMID: 16855180; PubMed Central PMCID: PMCPmc2613279.

11. Brownson RC, Chriqui JF, Stamatakis KA. Understanding evidence-based public health policy. American journal of public health. 2009;99(9):1576-1583.

12. Mudaliar U,Zabetian A, Goodman M, Echouffo-Tcheugui JB, Albright AL, Gregg EW, et al. Cardiometabolic Risk Factor Changes Observed in Diabetes Prevention Programs in US Settings: A Systematic Review and Meta-analysis. PLoS medicine. 2016;13(7):e1002095. Epub 2016/07/28. doi: 10.1371/journal.pmed.1002095. PubMed PMID: 27459705; PubMed Central PMCID: PMCPmc4961455.

13. Rahamon SK, Charles-Davies MA, Akinlade KS, Olaniyi JA, Fasanmade AA, Oyewole OE, et al. Impact of Dietary Intervention on selected biochemical Indices of Inflammation and Oxidative Stress in Nigerians with Metabolic Syndrome: a pilot study. European Journal of Nutrition \& Food Safety. 2014:137-149.

14. Rahamon SK, Fabian UA, Charles-Davies MA, Olaniyi JA, Fasanmade AA, Akinlade KS, et al. Changes in mediators of inflammation and pro-thrombosis after 12 months of dietary modification in adults with metabolic syndrome. African health sciences. 2017;17(2):453-462.

15. Charles-Davies MA, Arinola O, Fasanmade A, Olaniyi J, Oyewole O, Owolabi $\mathrm{M}$, et al. Indices of metabolic syndrome in 534 apparently healthy Nigerian traders. J US-China Med Sci. 2012;9:91-100.

16. Executive Summary of The Third Report of The National Cholesterol Education Program (NCEP) Expert Panel on Detection, Evaluation, And Treatment of High Blood Cholesterol In Adults (Adult Treatment Panel III). Jama. 2001;285(19):2486-2497. Epub 2001/05/23. doi: 10.1001/ jama.285.19.2486. PubMed PMID: 11368702.

17. Martinez-Gonzalez MA, Garcia-Arellano A, Toledo E, Salas-Salvado J, Buil-Cosiales P, Corella D, et al. A 14-item Mediterranean diet assessment tool and obesity indexes among high-risk subjects: the PREDIMED trial. PloS one. 2012;7(8):e43134. Epub 2012/08/21. doi: 10.1371/journal. pone.0043134. PubMed PMID: 22905215; PubMed Central PMCID: PMCPmc3419206.

18. Friedewald WT, Levy RI, Fredrickson DS. Estimation of the concentration of low-density lipoprotein cholesterol in plasma, without use of the preparative ultracentrifuge. Clinical chemistry. 1972;18(6):499-502.

19. Magkos F, Yannakoulia M, Chan JL, Mantzoros CS. Management of the metabolic syndrome and type 2 diabetes through lifestyle modification. Annual review of nutrition. 2009;29:223-256. Epub 2009/04/30. doi: 10.1146/annurev-nutr-080508-141200. PubMed PMID: 19400751; PubMed Central PMCID: PMCPmc5653262. 
20. Mumu SJ, Saleh F, Ara F, Afnan F, Ali L. Non-adherence to life-style modification and its factors among type 2 diabetic patients. Indian journal of public health. 2014;58(1): 4044. Epub 2014/04/22. doi: 10.4103/0019-557x.128165. PubMed PMID: 24748356.

21. Hanko B, Kazmer M, Kumli P, Hragyel Z, Samu A, Vincze Z, et al. Self-reported medication and lifestyle adherence in Hungarian patients with Type 2 diabetes. Pharmacy world \& science: PWS. 2007;29(2):58-66. Epub 2006/12/26. doi: 10.1007/s11096-006-9070-2. PubMed PMID: 17187222.

22. Serour M, Alqhenaei H, Al-Saqabi S, Mustafa AR, BenNakhi A. Cultural factors and patients' adherence to lifestyle measures. The British journal of general practice: the journal of the Royal College of General Practitioners. 2007;57(537):291-295. Epub 2007/03/31. PubMed PMID: 17394732; PubMed Central PMCID: PMCPmc2043336.

23. Ganiyu AB, Mabuza LH, Malete NH, Govender I, Ogunbanjo GA. Non-adherence to diet and exercise recommendations amongst patients with type 2 diabetes mellitus attending Extension II Clinic in Botswana. African journal of primary health care \& family medicine. 2013;5(1).

24. Mohammed MA, Sharew NT. Adherence to dietary recommendation and associated factors among diabetic patients in Ethiopian teaching hospitals. The Pan African medical journal. 2019;33:260. Epub 2019/11/07. doi: 10.11604/pamj.2019.33.260.14463. PubMed PMID: 31692826; PubMed Central PMCID: PMCPmc6814932.

25. Kennedy-Martin T, Boye KS, Peng X. Cost of medication adherence and persistence in type 2 diabetes mellitus: a literature review. Patient preference and adherence. 2017;11:1103-1117. Epub 2017/07/20. doi: 10.2147/ppa. s136639. PubMed PMID: 28721024; PubMed Central PMCID: PMCPmc5501621.

26. Eriksson K-F, Lindgärde F. Prevention of Type 2 (noninsulin-dependent) diabetes mellitus by diet and physical exercise The 6-year Malmö feasibility study. Diabetologia. 1991;34(12):891-898.

27. Fan $\mathrm{H}$, Li X, Zheng L, Chen $\mathrm{X}$, Lan $\mathrm{Q}, \mathrm{Wu} \mathrm{H}$, et al. Abdominal obesity is strongly associated with Cardiovascular Disease and its Risk Factors in Elderly and very Elderly Community-dwelling Chinese. Scientific reports. 2016;6:21521. Epub 2016/02/18. doi: 10.1038/ srep21521. PubMed PMID: 26882876; PubMed Central PMCID: PMCPmc4756331.

28. Bell RA, Chen H, Saldana S, Bertoni AG, Effoe VS, Hairston KG, et al. Comparison of Measures of Adiposity and Cardiovascular Disease Risk Factors Among African American Adults: the Jackson Heart Study. Journal of racial and ethnic health disparities. 2018;5(6):12301237. Epub 2018/02/11. doi: 10.1007/s40615-018-0469-y. PubMed PMID: 29427252; PubMed Central PMCID: PMCPmc6085149.

29. Aucott LS. Influences of weight loss on long-term diabetes outcomes. The Proceedings of the Nutrition Society. 2008:67(1):54-59. Epub 2008/02/01. doi: 10.1017/ s0029665108006022. PubMed PMID: 18234132.

30. Pi-Sunyer X, Blackburn G, Brancati FL, Bray GA, Bright R, Clark JM, et al. Reduction in weight and cardiovascular disease risk factors in individuals with type 2 diabetes: one-year results of the look AHEAD trial. Diabetes care. 2007;30(6):1374-1383. Epub 2007/03/17. doi: 10.2337/ dc07-0048. PubMed PMID: 17363746; PubMed Central PMCID: PMCPmc2665929.

31. Wing RR. Long-term effects of a lifestyle intervention on weight and cardiovascular risk factors in individuals with type 2 diabetes mellitus: four-year results of the Look AHEAD trial. Archives of internal medicine. 2010;170(17):1566-1575. Epub 2010/09/30. doi: 10.1001/ archinternmed.2010.334. PubMed PMID: 20876408; PubMed Central PMCID: PMCPmc3084497.
32. Dutton GR, Lewis CE. The Look AHEAD Trial: implications for lifestyle intervention in type 2 diabetes mellitus. Progress in cardiovascular diseases. 2015;58(1):69-75.

33. Gregg EW, Williamson DF. The relationship of intentional weight loss to disease incidence and mortality. Handbook of obesity treatment. 2002:125-143.

34. Jensen MD, Ryan DH, Apovian CM, Ard JD, Comuzzie AG, Donato KA, et al. $2013 \mathrm{AHA} / \mathrm{ACC} / \mathrm{TOS}$ guideline for the management of overweight and obesity in adults: a report of the American College of Cardiology/American Heart Association Task Force on Practice Guidelines and The Obesity Society. Journal of the American College of Cardiology. 2014;63(25 Part B):2985-3023.

35. Lu W, Resnick HE, Jablonski KA, Jones KL, Jain AK, Howard WJ, et al. Non-HDL cholesterol as a predictor of cardiovascular disease in type 2 diabetes: the strong heart study. Diabetes care. 2003;26(1):16-23. Epub 2002/12/28. doi: 10.2337/diacare.26.1.16. PubMed PMID: 12502653.

36. Wang K, Shan S, Zheng H, Zhao X, Chen C, Liu C. NonHDL-cholesterol to HDL-cholesterol ratio is a better predictor of new-onset non-alcoholic fatty liver disease than non-HDL-cholesterol: a cohort study. 2018;17(1): 196. doi: 10.1186/s12944-018-0848-8. PubMed PMID: 30131058.

37. Franz MJ, Boucher JL, Rutten-Ramos S, VanWormer JJ. Lifestyle weight-loss intervention outcomes in overweight and obese adults with type 2 diabetes: a systematic review and meta-analysis of randomized clinical trials. Journal of the Academy of Nutrition and Dietetics. 2015;115(9):1447-1463.

38. Metz JA, Stern JS, Kris-Etherton P, Reusser ME, Morris CD, Hatton DC, et al. A randomized trial of improved weight loss with a prepared meal plan in overweight and obese patients: impact on cardiovascular risk reduction. Archives of internal medicine. 2000;160(14):2150-2158. Epub 2000/07/25. doi: 10.1001/archinte.160.14.2150. PubMed PMID: 10904458.

39. Brehm BJ, Lattin BL, Summer SS, Boback JA, Gilchrist GM, Jandacek RJ, et al. One-year comparison of a highmonounsaturated fat diet with a high-carbohydrate diet in type 2 diabetes. Diabetes care. 2009;32(2):215-220. Epub 2008/10/30. doi: 10.2337/dc08-0687. PubMed PMID: 18957534; PubMed Central PMCID: PMCPmc2628682.

40. Davis NJ, Tomuta N, Schechter C, Isasi CR, Segal-Isaacson CJ, Stein D, et al. Comparative study of the effects of a 1-year dietary intervention of a low-carbohydrate diet versus a lowfat diet on weight and glycemic control in type 2 diabetes. Diabetes care. 2009;32(7):1147-1152. Epub 2009/04/16. doi: 10.2337/dc08-2108. PubMed PMID: 19366978; PubMed Central PMCID: PMCPmc2699720.

41. Esposito K, Maiorino MI, Ciotola M, Di Palo C, Scognamiglio $\mathrm{P}$, Gicchino $\mathrm{M}$, et al. Effects of a Mediterranean-style diet on the need for antihyperglycemic drug therapy in patients with newly diagnosed type 2 diabetes: a randomized trial. Annals of internal medicine. 2009;151(5):306-314.

42. Larsen RN, Mann NJ, Maclean E, Shaw J. The effect of high-protein, low-carbohydrate diets in the treatment of type 2 diabetes: a 12 month randomised controlled trial. Diabetologia. 2011;54(4):731-740.

43. Krebs J, Elley C, Parry-Strong A, Lunt H, Drury P, Bell D, et al. The Diabetes Excess Weight Loss (DEWL) Trial: a randomised controlled trial of high-protein versus high-carbohydrate diets over 2 years in type 2 diabetes. Diabetologia. 2012;55(4):905-914.

44. Guldbrand H, Dizdar B, Bunjaku B, Lindström T, Bachrach-Lindström $M$, Fredrikson $M$, et al. In type 2 diabetes, randomisation to advice to follow a lowcarbohydrate diet transiently improves glycaemic control compared with advice to follow a low-fat diet producing a similar weight loss. Diabetologia. 2012;55(8):2118-2127. 
45. Aso Y, Wakabayashi S, Yamamoto R, Matsutomo R, Takebayashi K, Inukai T. Metabolic syndrome accompanied by hypercholesterolemia is strongly associated with proinflammatory state and impairment of fibrinolysis in patients with type 2 diabetes: synergistic effects of plasminogen activator inhibitor- 1 and thrombin-activatable fibrinolysis inhibitor. Diabetes care. 2005;28(9):2211-2216. Epub 2005/08/27. doi: 10.2337/diacare.28.9.2211. PubMed PMID: 16123492.

46. Sethi JK, Vidal-Puig AJ. Thematic review series: adipocyte biology. Adipose tissue function and plasticity orchestrate nutritional adaptation. Journal of lipid research. 2007;48(6):1253-1262. Epub 2007/03/22. doi: 10.1194/ jlr.R700005-JLR200. PubMed PMID: 17374880; PubMed Central PMCID: PMCPmc4303760.

47. van Exel E, Gussekloo J, de Craen AJ, Frolich M, BootsmaVan Der Wiel A, Westendorp RG. Low production capacity of interleukin-10 associates with the metabolic syndrome and type 2 diabetes: the Leiden 85-Plus Study. Diabetes. 2002;51(4):1088-1092. Epub 2002/03/28. doi: 10.2337/ diabetes.51.4.1088. PubMed PMID: 11916930.
48. Rupp H, Maisch B. Abdominal fat and sympathetic overactivity. From calorie intake to postmenopausal hypertension. Herz. 2003;28(8):668-673. Epub 2003/12/23. doi: 10.1007/s00059-003-2517-5. PubMed PMID: 14689100.

49. Rahmouni K, Correia ML, Haynes WG, Mark AL. Obesityassociated hypertension: new insights into mechanisms. Hypertension. 2005;45(1):9-14.

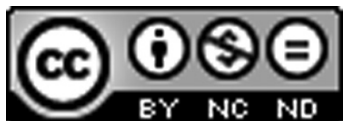

This work is licensed under a Creative Commons Attribution-Non Commercial-No Derivatives 4.0 International License. To view a copy of this license, visit http://creativecommons.org/licenses/by-nc-nd/4.0/ 